\title{
Awareness of obstetric fistula and associated factors among women in reproductive age group attending public hospitals in southwest Ethiopia, 2021
}

Dessalegn Nigatu Rundasa', Tarekegn Fekede Wolde ${ }^{1 *}\left(\mathbb{D}\right.$, Kenbon Bayisa Ayana $^{2}$ and Abeya Fufa Worke ${ }^{2}$

\begin{abstract}
Background: Obstetric fistula occurs in all developing countries but it is confined to the "fistula belt" across the northern half of Sub-Saharan Africa from Mauritania to Eritrea and in the developing countries of the Middle East and Asia. Ending obstetric fistula is critical to achieving Sustainable Development by 2030. So creating awareness on obstetrics fistula among women in the reproductive age group have a crucial role in reducing morbidity, mortality, and social stigma.
\end{abstract}

Objective: To assess awareness on obstetric fistula and its associated factors among reproductive-age women attending governmental hospitals in southwest Ethiopia, 2021.

Methods: An Institutional based cross-sectional study design was conducted among 413 women. The sample size was estimated by using a single population proportion formula. The collected data were coded and entered into EPI-data version 3.1 then exported to SPSS version 24 for descriptive and inferential analysis. Adjusted odds ratio (AOR) along with $95 \%$ confidence level was estimated to assess the strength of the association and variables with a $\mathrm{p}$-value $<0.05$ were considered to declare the statistical significance in the multivariable analysis in this study.

Results: In this study, a total of 400 clients have participated in the study. The mean ages of participants were 30.26 $(S D \pm 8.525)$ years old. Education of women who cannot read and write are $85 \%$ less likely to have good awareness than women who are above the secondary level of education $[A O R=0.162 ; 95 \% \mathrm{Cl}(0.081-0.364)]$. While Women who have primary education level are $83 \%$ less likely to have good awareness than women who are above the secondary level of education $[A O R=0.170 ; 95 \% \mathrm{Cl}(0.085-0.446)]$. In addition, This study shows women who have not heard about obstetric complications are $54 \%$ less likely to have awareness of obstetric fistula than those who heard about obstetric complications [AOR $=0.458 ; 95 \% \mathrm{Cl}(0.368-0.643)]$.

Conclusion: This study identifies that the educational level of women, history of pregnancy, distance to the nearby health institution, and awareness of obstetrics complications were the factors associated with awareness of reproductive age women on obstetrics fistula. Hence, increasing awareness on obstetric fistula plays a key role in averting this problem.

*Correspondence: fekedetarekegn88@gmail.com

1 Department of Nursing, College of Health Sciences, Mettu University, Metu, Ethiopia

Full list of author information is available at the end of the article permits use, sharing, adaptation, distribution and reproduction in any medium or format, as long as you give appropriate credit to the original author(s) and the source, provide a link to the Creative Commons licence, and indicate if changes were made. The images or other third party material in this article are included in the article's Creative Commons licence, unless indicated otherwise in a credit line to the material. If material is not included in the article's Creative Commons licence and your intended use is not permitted by statutory regulation or exceeds the permitted use, you will need to obtain permission directly from the copyright holder. To view a copy of this licence, visit http://creativecommons.org/licenses/by/4.0/. The Creative Commons Public Domain Dedication waiver (http://creativeco mmons.org/publicdomain/zero/1.0/) applies to the data made available in this article, unless otherwise stated in a credit line to the data. 


\begin{abstract}
Plain Language Summary
Globally, between 2 and 3 million women were affected by obstetric fistula. Moreover, obstetric fistula is common in developing nations, as around $60 \%$ of it was found in sub-Saharan the so-called fistula belt' and middle east Asia. This devastating condition adversely affects both the Physical and Mental health of the women. There is little research conducted concerning the health burdens of the obstetric fistula in southwest Ethiopia. Therefore, this article provides a better understanding of the level of awareness on obstetric fistula and barrier (factors) that hinders the early detection and treatment of obstetric fistula.

In this study, a cross-sectional study design was employed and data were collected from 400 women of the reproductive age group who visited public hospitals in the llu Aba Bor Zone. Our study shows that educational status, has not heard about complications of obstetric fistula, being far distant from the health facility, and not being pregnant were found to be factors that hinder the early detection and management of obstetric fistula. In conclusion, the finding of this study reported a low magnitude of level of awareness on obstetric fistula as compared to other previous studies.
\end{abstract}

Keywords: Awareness, Obstetric Fistula, Southwest Ethiopia

\section{Introduction}

Vaginal Fistula is an abnormal communication between the vagina and adjacent tubular structures-usually bladder and rectum-leading to continuous leakage of urine or feces-through the vagina [1]. Globally, an estimated 50,000 to 100,000 women develop fistula annually and about 2 million women currently live with fistula, which is a burden in almost 60 countries. Moreover, obstetric fistula appears in all developing countries, including African and middle east Asia, particularly confined across the northern half of sub-Saharan Africa from Mauritania to Eritrea as called the fistula belt' [2]. In Africa, Fistula is predominantly caused by prolonged and or obstructed labor; however, abdominal hysterectomy remains the most common cause of vaginal fistula in developed countries [3]. Currently, in Ethiopia, there are more than 110,000 women who have a vaginal fistula, of those less than 2000 women get treatment in the last 3 years [4].

Although Obstetric fistula is an indicator of the health system failing to provide accessible, timely, and appropriate intra-partum care [5]. Moreover, Obstetric fistula is devastating lifelong morbidity if left untreated, with severe medical, social, psychological, and economic consequences $[4,6-8]$. The underlying factors contributing to Obstetrics fistula including no skilled birth attendants $[9,10]$, poor health-seeking behavior, poor referral system and transportation [11,12] network [11, 13], age and physical maturity [12, 14-16], iatrogenic surgical damage[9], Educational status [10, 17, 18], sexual violence [16], poverty [11, 13], lack of awareness [5, 12, 15, 17] and not spacing between childbirths [9]. Despite these contributing factors, the main reason women prevent Fistula care was that lack of awareness of obstetric fistula prevention and treatment takes a lion share [6] and lack of awareness is a leading reason to seeking treatment [7]. Therefore, identify awareness and associated factors to have paramount importance to avert and or to reduce obstetric fistula among women of reproductive age categories. So that, measuring awareness and factors associated with obstetric fistula among women of reproductive age in southwest Ethiopia public hospitals is important as there are scares information in a study setting.

\section{Methods and materials}

\section{Study area and setting}

The study area was public hospitals in southwest Ethiopia. Which is located about $600 \mathrm{~km}$ away from the capital city, Addis Ababa, Ethiopia. It is bordered on the south by the south nation, nationality and Peoples', on the southwest by the Gambela, on the west by kelem wollega zone, on the north by west wollega zone, on the northwest by East wollega zone, and on the east by Jimma zone. The zone has an estimated area of 15,135.33 KM2. Moreover, the area has five hospitals and thirty-nine health centers. We used the five hospitals.

\section{Study design and period}

An institution-based cross-sectional study design was employed from December 30 to January 31, 2021.

\section{Source and study population}

All women in the reproductive age group (i.e., literally age b/n 15-49 years) attending governmental hospitals in southwest Ethiopia visiting Gynecology out Patient Department (OPD) and Ante Natal Care (ANC).

\section{Study unit}

Randomly selected reproductive age women and fulfill the inclusion criteria. 


\section{Eligibility criteria}

\section{Inclusion criteria}

All reproductive age group women those available at the time of the data collection period, volunteer and who are visiting the Gynecology Out Patient Department and Ante Natal Care.

\section{Exclusion criteria}

Women who refuse to participate in the study.

\section{Sample size determination}

The sample size was estimated by using a single population proportion formula. By considering the prevalence level of obstetric fistula that can estimate maximum sample size $(57.8 \%)$, marginal error (d) 0.05 , with $95 \%$ confidence interval certainty and margin of error 0.05 was considered. Finally, by adjusting the $10 \%$ non-respondent rate the sample size turned out 413 .

\section{Sampling procedure}

Five public hospitals were selected. A simple random sampling technique was employed after study subjects were proportionally allocated to each hospital.

\section{Operational definitions}

Awareness Conscious or informed about obstetric fistula cause, prevention, and presentation.

Good Awareness Participants who scored above the mean score whereas, Poor Awareness participants scored less than the mean.

\section{Data collection tool and technique}

A structured interviewer-administered adopted questionnaire was used for data collection. The questionnaire was first prepared in English and then translated into the local naïve language 'Afan Oromo' and re-translated back into English to maintain consistency by a fluent bilingual expert. Data were collected from each study subject by BSc holder midwifery in face-to-face interview from December 30 to January 30, 2021 at each hospital.

\section{Data quality control}

A two days training was given for both data collectors and supervisors on data collection procedure, accuracy, and completeness of the data. After the training, a pretest was carried out on the $5 \%$ of the sample was done in a similar population that was in another hospital, to ensure the quality and validity of the data. Finally, the supervisor checked for completeness on regular basis.

\section{Data processing and analysis}

Data were checked for completeness, clarity, and consistency. The data were entered into EPI- data version
3.1 and exported to SPSS version 24 statistical software for analysis. Descriptive statistics were employed. Logistic regression was used to see the association between dependent and independent variables. Statistical significance was declared at P-value less than 0.05 at $95 \% \mathrm{CI}$ as the cut of point. Odds Ratio at 95\% CI was used to identify the presence and strength of association.

\section{Ethical consideration}

To conduct the study an ethical approval was obtained from Institutional Review Board of College of Health Sciences, Mettu University, Ethiopia. Official letter of cooperation was written to south west health bureau from department of public health. Written, informed and signed consent was taken from respondents of age 18 and above after telling, the confidentiality was kept and the role of their participation is for research purpose.

\section{Results}

Socio-demographic characteristic

Out of a total of 413, 400 respondents were participated, with a response rate of $96.85 \%$. The mean age of participants was $30.26(\mathrm{SD} \pm 8.525)$ years old. More than half (55\%) of participants were Orthodox Christian in religion. The majority of participants were Oromo in ethnicity (Table1).

\section{Obstetric characteristic}

Out of a total, 205 (51.1\%) participants do not hear about obstetrical complications. Almost half of the participants (49.8\%) use modern family planning methods. Women who have less than three pregnancies are 170 (42.5\%) (Table 2).

\section{Awareness on obstetric fistula}

Women who have ever heard of obstetric fistula are 53\% and out of these, $34.6 \%$ of women get information from media about obstetric fistula. Moreover, $38.1 \%$ of them reported the inability to control urine as a symptom of obstetric fistula (Table 3).

Women who have a good awareness of causes, symptoms, and prevention are 177 (44.3\%), 219 (54.8\%), and 177 (44.3\%) respectively. General Obstetric fistula awareness of women in visiting hospitals in southwest Ethiopia is $50 \%$, which is poor awareness on obstetric fistula. (Fig. 1).

\section{Factors associated with awareness status on obstetric fistula}

In bivariate analysis, the result shows educational status of women, distance to the health center, modern contraceptive use, hearing about delivery complications, 
Table 1 Socio demographic characteristics of participants among women in reproductive age group attending public hospitals in southwest Ethiopia, $2021(n=400)$

\begin{tabular}{|c|c|c|}
\hline Variable & Frequency & Percent \\
\hline \multicolumn{3}{|l|}{ Age } \\
\hline$<$ Mean (30.26 years) & 208 & 52 \\
\hline > Mean (30.26 years) & 192 & 48 \\
\hline \multicolumn{3}{|l|}{ Religion } \\
\hline Orthodox Christian & 220 & 55.0 \\
\hline Muslim & 133 & 33.3 \\
\hline Catholic & 12 & 3 \\
\hline Protestant & 35 & 8.8 \\
\hline \multicolumn{3}{|l|}{ Ethnicity } \\
\hline Oromo & 256 & 64 \\
\hline Amhara & 98 & 24.5 \\
\hline Gurage & 29 & 7.3 \\
\hline Others & 17 & 4.3 \\
\hline \multicolumn{3}{|l|}{ Marital status } \\
\hline Single & 100 & 25.0 \\
\hline Married & 254 & 63.5 \\
\hline Divorced & 20 & 5.0 \\
\hline Separated & 11 & 2.8 \\
\hline Widowed & 15 & 3.8 \\
\hline \multicolumn{3}{|l|}{ Marriage age } \\
\hline $15-19$ & 112 & 28.0 \\
\hline $20-24$ & 142 & 35.5 \\
\hline $25-29$ & 26 & 6.5 \\
\hline $30-34$ & 5 & 1.3 \\
\hline $35-39$ & 1 & 0.3 \\
\hline \multicolumn{3}{|l|}{ Educational level } \\
\hline No formal education & 89 & 22.2 \\
\hline Primary education & 104 & 26.0 \\
\hline Secondary education & 112 & 28.0 \\
\hline Above secondary & 95 & 23.8 \\
\hline \multicolumn{3}{|l|}{ Occupation } \\
\hline House wife & 193 & 48.3 \\
\hline Student & 65 & 16.3 \\
\hline Farmer & 9 & 2.3 \\
\hline Merchant & 42 & 10.5 \\
\hline Government employee & 40 & 10.0 \\
\hline Private employee & 51 & 12.8 \\
\hline \multicolumn{3}{|c|}{ Monthly Income (Ethiopian Birr) } \\
\hline$\leq 1000$ & 167 & 41.8 \\
\hline $1001-2000$ & 129 & 32.3 \\
\hline $2001-3000$ & 54 & 13.5 \\
\hline $3001-4000$ & 25 & 6.3 \\
\hline $4001-5000$ & 25 & 6.3 \\
\hline
\end{tabular}

and history of pregnancy were found to have significant associations.
Table 2 Obstetric characteristic of participants among women in reproductive age group attending public hospitals in southwest Ethiopia, 2021

\begin{tabular}{|c|c|c|}
\hline Variable & Frequency & Percent \\
\hline \multicolumn{3}{|c|}{ Heard about obstetric complication } \\
\hline Yes & 195 & 48.9 \\
\hline No & 205 & 51.1 \\
\hline \multicolumn{3}{|c|}{ History of induced abortion ( $n=285)$} \\
\hline Yes & 62 & 21.8 \\
\hline No & 223 & 78.2 \\
\hline \multicolumn{3}{|c|}{ History of birth complication $(n=285)$} \\
\hline Yes & 122 & 42.8 \\
\hline No & 163 & 57.2 \\
\hline \multicolumn{3}{|c|}{ Contraceptive use } \\
\hline Yes & 197 & 49.3 \\
\hline No & 203 & 50.8 \\
\hline \multicolumn{3}{|c|}{ Type of contraceptive used $(n=197)$} \\
\hline Injectable & 106 & 53.8 \\
\hline Pills & 41 & 20.8 \\
\hline Implants & 35 & 17.8 \\
\hline IUCD & 12 & 6.1 \\
\hline Condom & 3 & 1.5 \\
\hline \multicolumn{3}{|c|}{ Have you ever an pregnant } \\
\hline Yes & 253 & 63.3 \\
\hline No & 147 & 36.8 \\
\hline \multicolumn{3}{|c|}{ Age at 1st pregnancy } \\
\hline $15-19$ & 112 & 39.2 \\
\hline $20-24$ & 142 & 49.7 \\
\hline $25-29$ & 26 & 9.1 \\
\hline $30-34$ & 5 & 1.7 \\
\hline $35-39$ & 1 & 0.3 \\
\hline \multicolumn{3}{|c|}{ Number of parity } \\
\hline $1-3$ & 170 & 42.5 \\
\hline $4-6$ & 90 & 22.5 \\
\hline $7-9$ & 21 & 5.3 \\
\hline $10-12$ & 4 & 1.0 \\
\hline
\end{tabular}

In multivariate analysis, the result showed a significant association between history of pregnancy and the odds of having good awareness. Those reproductive age group who had a history of pregnancy were $68 \%$ less likely to have a good awareness of obstetrics fistula prevention than their counterparts $[\mathrm{AOR}=0.399 ; 95 \% \mathrm{CI}$ (0.241-0.661)]. Distance to the nearby health institution (hospital), those who lived above half an hour foot distance were $65 \%$ less likely to have good awareness than those living near to health facility $[\mathrm{AOR}=0.355 ; 95 \% \mathrm{CI}$ (0.212-0.594)]. Education of women who cannot read and write are $85 \%$ less likely to have good awareness than women who are above the secondary level of education 
Table 3 Participants characteristics about Awareness on Obstetric fistula among women in reproductive age group attending public hospitals in southwest Ethiopia, 2021

\begin{tabular}{lcc}
\hline Variable & Frequency & Percent \\
\hline Ever heard about obstetric fistula & 212 & \\
Yes & 188 & 43.0 \\
No & & \\
Symptoms of obstetric fistula you heard & 82 & 38.1 \\
Unable to control urine & 4 & 1.9 \\
Unable to control feces & 58 & 27.0 \\
Unable to control urine and feces & 23 & 10.7 \\
Bleeding and pain during sex & 23 & 10.7 \\
Abnormal Vaginal discharge & 25 & 11.6 \\
Irritation during urination & & \\
Source of information about obstetric Fistula & 56 & 26.2 \\
Health facility & 47 & 22.0 \\
Family and friends & 15 & 7.0 \\
School & 74 & 34.6 \\
Media & 22 & 10.3 \\
Victim of fistula &
\end{tabular}

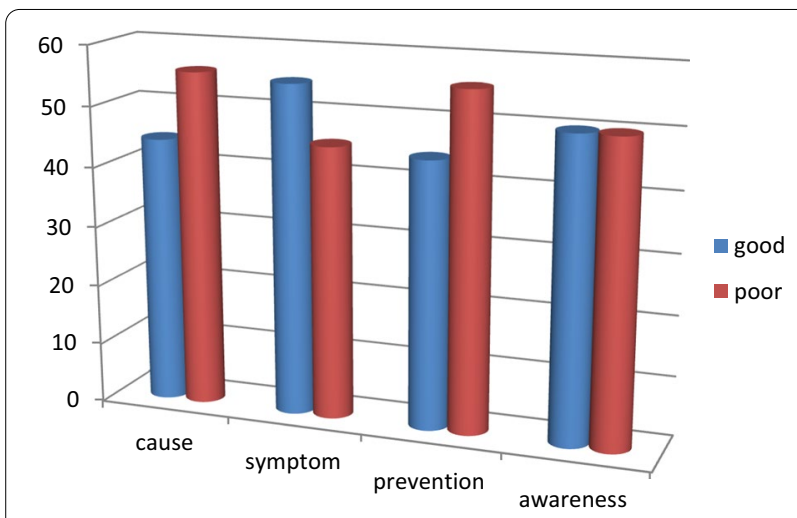

Fig. 1 The status of Women's awareness on obstetric fistula at public hospitals in southwest Ethiopia, 2021

$[\mathrm{AOR}=0.162 ; 95 \% \mathrm{CI}(0.081-0.364)]$. Women who have primary education level are $83 \%$ less likely to have good awareness than women who are above the secondary level of education $[\mathrm{AOR}=0.170$; $95 \% \mathrm{CI}(0.085-0.446)$ ] and women who have secondary education level are $70 \%$ less likely to have good awareness than women who are above the secondary level of education $[\mathrm{AOR}=0.299$; 95\% CI (0.153-0.584)] In addition, my study shows women's who have not heard about obstetric complication are $54 \%$ less likely to have awareness on obstetric fistula than those who heard about obstetric complication $[\mathrm{AOR}=0.458$; 95\% CI (0.368-0.643)] (Table 4).

\section{Discussion}

In this study, half of respondents $50 \%$ at $95 \%$ confidence interval (34.62-45.37) have had good awareness about obstetric fistula. Despite the problems associated with obstetric fistula, many women are not aware of the obstetric fistula. It may be difficult to control a disease that people are not aware of. This finding may also imply that these women were not aware of how to prevent obstetric fistula. This finding was lower when compared with the study done in Delanta district which is $55.4 \%[19,20]$, the difference might be due to sampling size and study participants. Our finding was consistent when compared to a study done in Ghana which was $47.6 \%$ [15].

This study showed that 212 (53\%) reproductive age group women have heard obstetric fistula this result is higher than EDHS, 2016 of which 2 in 5 women interviewed in the survey had heard of obstetric fistula (39\%) [2].This difference might be due to EDHS takes sample from different regions of Ethiopia which have different geographical location, social and cultural factors and my study took only participants who visit hospitals.

My study shows there is significant association between women awareness and their educational level, women's who cannot read and write are $84 \%$ less likely to have good awareness than women who are above secondary level of education. Women's who have primary education level are $83 \%$ less likely to have good awareness than women who are above secondary level of education and women's who have secondary education level are $70 \%$ less likely to have good awareness than women who are above secondary level of education. This shows that when education level is improved the awareness comes more improved. The finding also supported by study conducted in Cameroonian women which shows $53 \%$ of women who had no previous knowledge on obstetric fistula were generally the illiterate [3]. Another study, which supports my study, is survey on obstetric fistula awareness which was done in Northern Ghana, how that Level of education of the participants had a significant influence on.

Awareness the level of fistula with about 50.2\% those with higher education aware of as.

Compared to $49.8 \%$ who had no knowledge about fistula the result of this study showed that there were a significant association tween women's awareness and distance to the nearby health center. Women living in areas where hospital or health institution is found at a distance more than half an hour (on foot) from the home they are living, their awareness is $65 \%$ less likely to good than those living in areas which are found at a distance less than or equal to half an hour. This can supported by studies in Ethiopia that identifies 
Table 4 Multivariate analysis showing the impact of selected associated factors of obstetric fistula among reproductive age women in in public hospitals in southwest Ethiopia, 2021

\begin{tabular}{|c|c|c|c|c|c|}
\hline \multirow[t]{2}{*}{ Variable } & \multicolumn{4}{|c|}{ Awareness on OF } & \multirow[b]{2}{*}{$\mathrm{p}$ value } \\
\hline & Good & Poor & COR $(95 \% \mathrm{Cl})$ & AOR $(95 \% \mathrm{Cl})$ & \\
\hline \multicolumn{6}{|l|}{ Women education } \\
\hline Can't read and write & $30(33.7 \%)$ & $59(66.3 \%)$ & $0.119(0.060-0.234)$ & $0.162(0.081-0.364)$ & $0.000^{* *}$ \\
\hline Primary & $41(39.4 \%)$ & $63(60.6 \%)$ & $0.152(0.080-0.290)$ & $0.170(0.085-0.446)$ & $0.001 *$ \\
\hline Secondary & $52(46.4 \%)$ & $60(53.6 \%)$ & $0.203(0.108-0.382$ & $0.299(0.153-0.584)$ & $0.000^{* *}$ \\
\hline Above secondary & $77(81.1 \%)$ & $18(18.9 \%)$ & 1 & & \\
\hline \multicolumn{6}{|l|}{ HDC } \\
\hline No & $81(39.7 \%)$ & $123(60.3 \%)$ & $0.430(0.288-0.642)$ & $0.458(0.368-0.678)$ & $0.000^{* *}$ \\
\hline Yes & $118(60.5 \%)$ & 77 (39.5\%) & 1 & 1 & \\
\hline \multicolumn{6}{|c|}{ Distance to HF on foot by minutes } \\
\hline$>30$ & $36(26.5 \%)$ & $100(73.5 \%)$ & $0.220(0.139-0.346)$ & $0.355(0.212-0.594)$ & $0.000^{* *}$ \\
\hline$\leq 30$ & $164(62.3 \%)$ & $100(37.7 \%)$ & 1 & 1 & \\
\hline \multicolumn{6}{|l|}{ Contraceptive use } \\
\hline No & $91(44.8 \%)$ & $112(55.2 \%)$ & $0.656(0.442-0.973)$ & $1.101(0.601-2.013)$ & 0.712 \\
\hline Yes & 109 (55.3\%) & $88(44.7 \%)$ & 1 & 1 & \\
\hline \multicolumn{6}{|l|}{ Ever pregnancy } \\
\hline No & $46(31.3 \%)$ & 101 (68.7\%) & $0.293(0.190-0.450)$ & $0.399(0.241-0.661)$ & $0.002^{*}$ \\
\hline Yes & 154 (60.9\%) & 99 (39.1\%) & 1 & 1 & \\
\hline
\end{tabular}

OF obstetric-fistula, HF health facility, HDC heard delivery complication

**Significant association $(p<0.01)$

distance to the health care facility was linked with poor knowledge related to fistula and poor health seeking behavior which increases the likelihood of more fistula cases [4]. A study on awareness to health knowledge in Western China showed that health knowledge declined as the distance from the nearby health institution increases [5].This might cause of, as the health facility comes near women's are to visit the facility cause they do not need transportation.

In my study women's who have not heard about obstetric complication are $54 \%$ less likely to have awareness on obstetric fistula than those who heard about obstetric complication. This finding is supported by study done in Amhara region which shows the presence of awareness about complications of delivery other than obstetrics fistula was significantly associated with sufficient knowledge on obstetrics fistula. This might cause of the issue that obstetrics fistula can also informed together with dangers of pregnancy since it is among the child birth complications.

This study showed that good awareness on obstetric fistula tended to more common among women with previous pregnancy history than those without. Those who had history of pregnancy were $60 \%$ less likely to have good awareness. This finding is supported by study done in Delanta district which shows, women with no pregnancy history were $87 \%$ times less likely to have sufficient knowledge. The finding is also consistent with other studies which showed non-exposure to pregnancy prevents women's knowledge on obstetrics fistula by $80 \%$ [6].

\section{Conclusion}

The finding indicates that $50 \%$ of reproductive age women have poor awareness about obstetric fistula, and Educational level of women, history of pregnancy, distance from health facility and awareness on obstetrics complications were the factors associated with awareness of reproductive age women on obstetrics fistula.

Limitations As it is a cross sectional study; it cannot show cause-effect relationship between factors and outcome variable and the same to other behavioral studies, respondents might not reply openly to sensitive and private questions.

\section{Abbreviations}

CS: Caesarean section; EDHS: Ethiopian demographic and health survey; $\mathrm{DH}$ : Darimu hospital; FGD: Focused group discussions; IDI: In-depth interviews; IRB: Institutional Review Board; OF: Obstetric fistula; MKH: Mettu Karl Hospital; RVF: Recto vaginal fistula; SPSS: Statically package for social sciences; TBA: 
Traditional birth attendants; UNFPA: United Nation Fund for Population Agency; USAID: United States Agency for International Developments; WF: Vesico-vaginal fistula.

\section{Acknowledgements}

We are thankful to the College of Health Sciences, Mettu University, for sponsoring the project. We would like to thank the llu Aba Bor health bureau to permitting us to conduct the study and providing the preliminary information. Lastly, we would like to extend thanks to study participants, supervisors, and data collectors.

\section{Authors' contributions}

TF, DN, KB and AF inception designed the proposal, data analysis, interpretation, manuscript draft, revised the manuscript and wrote the paper. TF and DN participate in data collection and entry. KB and AF participate in analysis. All Authors read and approved the final paper.

\section{Funding}

Not applicable.

\section{Availability of data and materials}

All data supporting our findings will be shared upon request.

\section{Declarations}

\section{Ethics approval and consent to participate}

Not applicable.

\section{Consent for publications}

Not applicable.

\section{Competing interests}

The authors declare that they have no competing of interest.

\section{Author details}

'Department of Nursing, College of Health Sciences, Mettu University, Metu, Ethiopia. ${ }^{2}$ Department of Midwifery, College of Health Sciences, Mettu University, Metu, Ethiopia.

Received: 2 June 2021 Accepted: 26 August 2021

Published online: 15 September 2021

\section{References}

1. Disease Control Priorities, Third Edition (Volume 1): Essential Surgery. Dis Control Priorities [Internet]. [cited 2021 May 11]; https://elibrary.world bank.org/doi/pdf/10.1596/978-1-4648-0346-8.

2. Treuthart MP. No woman, no cry-ending the war on Women Worldwide and the International Violence against Women Act (I-VAWA). Boston Univ Int Law J. 2015;33:73.

3. Miller EA, Webster GD. Current management of vesicovaginal fistulae. Curr Opin Urol. 2001;11(4):417-21.

4. Maheu-Giroux M, Filippi V, Samadoulougou S, Castro MC, Maulet N, Meda $\mathrm{N}$, et al. Prevalence of symptoms of vaginal fistula in 19 sub-Saharan Africa countries: a meta-analysis of national household survey data. Lancet Glob Health. 2015:3(5):e271-8.

5. SciELO_Public Health—Measuring the incidence and prevalence of obstetric fistula: approaches, needs and recommendations Measuring the incidence and prevalence of obstetric fistula: approaches, needs and recommendations [Internet]. [cited 2021 May 14]. https://www.scielosp. org/article/bwho/2015.v93n1/60-62/en/.
6. Baker Z, Bellows B, Bach R, Warren C. Barriers to obstetric fistula treatment in low-income countries: a systematic review. Trop Med Int Health. 2017;22(8):938-59.

7. Causes and consequences of obstetric fistula in Ethiopia: A literature review-Indian Journals [Internet]. [cited 2021 May 21]. https://www.india njournals.com/ijor.aspx?target $=$ ijor:ijmrhs\&volume $=2 \&$ issue $=2 \&$ article $=$ 024.

8. Trajectories of women's physical and psychosocial health following obstetric fistula repair in Uganda: a longitudinal study [Internet]. [cited 2021 May 21]. https://onlinelibrary.wiley.com/doi/epdf/10.1111/tmi. 13178.

9. den Hollander GC, Janszen EWM. Obstetric fistulas in Uganda: scoping review using a determinant of health approach to provide a framework for health policy improvement. BMC Pregnancy Childbirth. 2020;20(1):257.

10. Profile and outcome of patients with recurrent urogenital fistula in a fistula centre in Nigeria | SpringerLink [Internet]. [cited 2021 May 21]. https://link.springer.com/article/10.1007/s00192-018-3738-8.

11. Swain D, Parida SP, Jena SK, Das M, Das H. Prevalence and risk factors of obstetric fistula: implementation of a need-based preventive action plan in a South-eastern rural community of India. BMC Womens Health. 2020;20(1):40.

12. Balcha WF, Nigussie AA, Beyene FY, Tesfu AA. Awareness and Its associated factors of obstetrics fistula among antenatal care attendees in Injibara Town Health Institutions, Awi Zone, North West, Ethiopia, 2019. J Pregnancy. 2020;1(2020):1-7.

13. A review of surgical procedures to repair obstetric fistula-Pope2020 — International Journal of Gynecology; Obstetrics—Wiley Online Library [Internet]. [cited 2021 May 21]. https://obgyn.onlinelibrary.wiley. com/doi/full/10.1002/ijgo.13035.

14. Gebertsadik AW, Gebrehiwot GG, Desta AA, Ajemu KF, Berhe AA, Woldearegay TW, et al. Factors associated with obstetric fistula among reproductive age women in Ethiopia, community based, case control study [Internet]. In Review; 2020 [cited 2021 May 21]. https://www.resea rchsquare.com/article/rs-61513/v1.

15. Knowledge of obstetric fistula among prenatal clinic attendees and midwives in Mfantsiman municipality, Ghana-Azanu - 2020-International Journal of Gynecology; Obstetrics-Wiley Online Library [Internet]. [cited 2021 May 21]. https://obgyn.onlinelibrary.wiley.com/doi/full/10.1002/ ijgo.13034.

16. Cowgill KD, Bishop J, Norgaard AK, Rubens CE, Gravett MG. Obstetric fistula in low-resource countries: an under-valued and under-studied problem - systematic review of its incidence, prevalence, and association with stillbirth. BMC Pregnancy Childbirth. 2015;15(1):193.

17. Muleta M, Fantahun M, Tafesse B, Hamlin EC, Kennedy RC. Obstetric fistula in rural Ethiopia. East Afr Med J [Internet]. 2008 [cited 2021 May 21];84(11). http://www.ajol.info/index.php/eamj/article/view/9572.

18. Mwanri L, Gatwiri GJ. Injured bodies, damaged lives: experiences and narratives of Kenyan women with obstetric fistula and Female Genital Mutilation/Cutting. Reprod Health. 2017;14(1):38.

19. Masresha SA, Kassaw MW, Alen GD. Adolescent marriage in northeast Ethiopia: the case of Delanta district. Glob Soc Welf. 2021;8(2):171-9.

20. Jacobson LE, Marye MA, Phoutrides E, Nardos R. Provider perspectives on persistent urinary incontinence following obstetric fistula repair in Ethiopia. Front Glob Womens Health. 2020;1:557224.

\section{Publisher's Note}

Springer Nature remains neutral with regard to jurisdictional claims in published maps and institutional affiliations. 